\title{
ERRATUM
}

\section{Erratum to: Ethical Challenges Come Home}

\author{
Matthew K. Wynia, MD, MPH' and James E. Sabin, MD² \\ ${ }^{1}$ Institute for Ethics, American Medical Association, Chicago, IL, USA; ${ }^{2}$ Harvard Pilgrim Health Care, Boston, MA, USA.
}

J Gen Intern Med 28(1):164

DOI: $10.1007 / \mathrm{s} 11606-012-2285-0$

() Society of General Internal Medicine 2012

\section{Erratum to: J Gen Intern Med \\ DOI 10.1007/s11606-012-2232-0}

$\mathrm{O}$ n page 1 of this commentary on Braddock, et al's, The Patient Centered Medical Home: An Ethical Analysis of Prinicples and Practice, authorship of the Braddock et al. article is attributed to members of the American College of Physicians (ACP) Ethics, Professionalism and Human Rights Committee. In fact, the Braddock et al. article was the result of a joint effort of the ACP committee and the Society of General Internal Medicine's Ethics Committee. We sincerely regret this omission.

Corresponding Author: Matthew K. Wynia, MD, MPH; Institute for Ethics, American Medical Association, 515 N State St, Chicago, IL 60654, USA (e-mail: matthew.wynia@ama-assn.org).

The online version of the original article can be found at http:// dx.doi.org/10.1007/s11606-012-2232-0.

Published online November 21, 2012 